\title{
Article \\ Environment-Friendly Zinc Oxide Nanorods-Grown Cellulose Nanofiber Nanocomposite and Its Electromechanical and UV Sensing Behaviors
}

\author{
Lindong Zhai ${ }^{1}{ }^{\circledR}$, Hyun-Chan Kim ${ }^{1}{ }^{1}$, Ruth M. Muthoka ${ }^{1}$, Muhammad Latif ${ }^{1}$, Hussein Alrobei ${ }^{2}{ }^{\circledR}$, \\ Rizwan A. Malik ${ }^{3}$ and Jaehwan Kim ${ }^{1, * \mathbb{D}}$ \\ 1 CRC for Nanocellulose Future Composites, Inha University, Incheon 22212, Korea; \\ duicaofei@naver.com (L.Z.); kim_hyunchan@naver.com (H.-C.K.); mwongelinruth@gmail.com (R.M.M.); \\ mlatif8482@gmail.com (M.L.) \\ 2 Department of Mechanical Engineering, Prince Sattam bin Abdul Aziz University, \\ AlKharj 11942, Saudi Arabia; h.alrobei@psau.edu.sa \\ 3 Department of Metallurgy and Materials Engineering, University of Engineering and Technology, \\ Taxila 47050, Pakistan; rizwanmalik48@yahoo.com \\ * Correspondence: jaehwan@inha.ac.kr; Tel.: +82-32-874-7325
}

\section{check for} updates

Citation: Zhai, L.; Kim, H.-C.; Muthoka, R.M.; Latif, M.; Alrobei, H.; Malik, R.A.; Kim, J.

Environment-Friendly Zinc Oxide Nanorods-Grown Cellulose Nanofiber Nanocomposite and Its Electromechanical and UV Sensing Behaviors. Nanomaterials 2021, 11, 1419. https://doi.org/10.3390/ nano11061419

Academic Editor: Vincent Consonn

Received: 25 April 2021

Accepted: 26 May 2021

Published: 27 May 2021

Publisher's Note: MDPI stays neutral with regard to jurisdictional claims in published maps and institutional affiliations.

Copyright: (c) 2021 by the authors. Licensee MDPI, Basel, Switzerland. This article is an open access article distributed under the terms and conditions of the Creative Commons Attribution (CC BY) license (https:// creativecommons.org/licenses/by/ $4.0 /)$.

\begin{abstract}
This paper reports a genuine environment-friendly hybrid nanocomposite made by growing zinc oxide $(\mathrm{ZnO})$ nanorods on cellulose nanofiber $(\mathrm{CNF})$ film. The nanocomposite preparation, characterizations, electromechanical property, and ultraviolet (UV) sensing performance are explained. CNF was extracted from the pulp by combining the 2,2,6,6-tetramethylpiperidine-1-oxyl radical (TEMPO) oxidation and the aqueous counter collision (ACC) methods. The CNF film was fabricated using doctor blade casting, and $\mathrm{ZnO}$ nanorods were grown on the CNF film by seeding and by a hydrothermal method. Morphologies, optical transparency, mechanical and electromechanical properties, and UV sensing properties were examined. The nanocomposite's optical transparency was more than $80 \%$, and the piezoelectric charge constant $d_{31}$ was 200 times larger than the CNF film. The UV sensing performance of the prepared $\mathrm{ZnO}-\mathrm{CNF}$ nanocomposites was tested in terms of $\mathrm{ZnO}$ concentration, UV irradiance intensity, exposure side, and electrode materials. A large aspect ratio of $\mathrm{ZnO}$ nanorods and a work function gap between $\mathrm{ZnO}$ nanorods and the electrode material are essential for improving the UV sensing performance. However, these conditions should be compromised with transparency. The use of CNF for ZnO-cellulose hybrid nanocomposite is beneficial not only for electromechanical and UV sensing properties but also for high mechanical properties, renewability, biocompatibility, flexibility, non-toxicity, and transparency.
\end{abstract}

Keywords: cellulose nanofiber; zinc oxide; nanocomposite; electromechanical property; UV sensing

\section{Introduction}

Organic and inorganic functional nanocomposites combine advantages of the individual materials that surpass parental material properties. They can achieve high mechanical strength, electrical conductivity, thermal conductivity, antibacterial, gas barrier, flame retardancy, electromagnetic shielding, optical transparency, energy harvesting, and actuating properties [1]. Cellulose nanofiber (CNF) is an outstanding organic material composed of nano-sized cellulose fibrils with a high aspect ratio [2-7]. The width of CNF is typically in the range of 5-20 nm, and its length is typically up to several micrometers. Cellulose molecules can form microfibrils during the biosynthesis process by forming inter- and intra-molecular hydrogen bonds [4]. CNF extracted from plants by the top-down approach has excellent properties: not only renewability, biodegradability, abundance, low price, and light weight but also high optical transparency, outstanding mechanical properties, and low thermal expansion coefficient [6]. Thus, CNF can be a building block of future 
materials applied for structural composites, coatings, cosmetics, 3D printing, sensors, soft actuators, flexible electronics, energy devices, and flexible displays [8-13].

Inorganic nanomaterials can improve the functional properties of organic-inorganic functional nanocomposites. The inorganic nanomaterials can be either blended or coated with/on the polymer nanocomposites [14,15]. Owing to its benefits in terms of wide bandgap $(3.37 \mathrm{eV})$, high exciton binding energy $(60 \mathrm{meV})$, ultraviolet $(\mathrm{UV})$ response, optical transparency, highly electrical conductivity, and piezoelectricity, zinc oxide $(\mathrm{ZnO})$ has been widely studied [16,17]. $\mathrm{ZnO}$ is broadly used in electronic devices, hybrid diodes, energy harvesters, piezoelectric devices, field-effect transistors, gas sensors, photovoltaics, and UV sensors [18-25]. It can be quickly grown on various substrates, including metal, glass, silicon, sapphire, plastics, polymers, and cellulose [20,26-32].

With increasing interest in wearable devices, the $\mathrm{ZnO}$-cellulose hybrid composite is attractive because it can bridge $\mathrm{ZnO}^{\prime}$ s functional properties and renewability and flexibility of cellulose. Recently $\mathrm{ZnO}$ nanorods grown on paper and cellulose have been reported [33-38]. A flexible and transparent cellulose- $\mathrm{ZnO}$ hybrid nanocomposite was prepared by direct $\mathrm{ZnO}$ seeding and hydrothermal $\mathrm{ZnO}$ nanorod growth on a regenerated cellulose film [35,36]. A zinc oxide nanolayer was uniformly formed on a regenerated cellulose film using a solution-based hydrothermal process, which shows a drastic improvement of its electromechanical behavior [37]. However, they used regenerated cellulose, which was prepared using special solvents, such as $\mathrm{LiCl} / \mathrm{DMAc}$ [39]. It is essential to use CNF film instead of regenerated cellulose in cellulose- $\mathrm{ZnO}$ hybrid nanocomposites because the particular solvent usage can be eliminated.

Thus, this research aimed to prepare a genuine environment-friendly $\mathrm{ZnO}-\mathrm{CNF}$ nanocomposite (ZCN) by growing $\mathrm{ZnO}$ nanorods on a CNF film according to the hydrothermal method. By using CNF instead of regenerated cellulose, the genuine environmentfriendly $\mathrm{ZnO}$-cellulose nanocomposite was prepared. Since CNF possesses numerous hydroxyl groups on its surface, $\mathrm{ZnO}$ can be efficiently anchored on the CNF film surface. This paper illustrates the $\mathrm{CNF}$ isolation, $\mathrm{CNF}$ film preparation, and the $\mathrm{ZnO}$ nanorods growth on the CNF film. The $\mathrm{ZnO}$ nanorods were grown by adopting the seeding process, followed by the hygrothermal process [37]. The morphologies, optical transparency, mechanical, electromechanical, and UV sensing properties of the prepared ZCN were investigated.

\section{Materials and Methods}

\subsection{Materials}

Hardwood (HW) pulp was received from Hansol Paper and Pulp Co. (Jeonju, Korea). HW bleached kraft pulp in dried pad form is a combination of Aspen and Poplar, and its alpha-cellulose $(\alpha)$ content is $85.7 \%$, and viscosity is $14.6 \mathrm{cPs}$. 2,2,6,6-tetramethylpiperidine1-oxyl radical (TEMPO, 98\%), sodium bromide ( $\mathrm{NaBr}, 99 \%)$, sodium hypochlorite $(\mathrm{NaClO}$, $15 \%)$, and hydrochloric acid $(\mathrm{HCl}, 37 \%)$ were purchased from Sigma-Aldrich St. Louis, MO, USA, and Sodium hydroxide ( $\mathrm{NaOH}, 98 \%$ ) was purchased from Daejung Chemical, Busan, Korea. They were used to oxidize HW pulp further to extract CNF. Zinc acetate dihydrate $\left(\mathrm{Zn}\left(\mathrm{CH}_{3} \mathrm{COO}\right)_{2} \cdot 2 \mathrm{H}_{2} \mathrm{O}\right.$, reagent grade $98 \%$ ) was purchased from Sigma-Aldrich, and ethyl alcohol anhydrous $\left(\mathrm{C}_{2} \mathrm{H}_{5} \mathrm{OH}\right.$, purity $\left.99.5 \%\right)$ was purchased from Daejung Chemical. Zinc nitrate hexahydrate $\left(\mathrm{Zn}\left(\mathrm{NO}_{3}\right)_{2} \cdot 6 \mathrm{H}_{2} \mathrm{O}\right.$, reagent grade $\left.98 \%\right)$ and hexamethylenetetramine (HMT, $\left(\mathrm{CH}_{2}\right)_{6} \mathrm{~N}_{4}$, reagent grade 99\%) were purchased from Sigma-Aldrich. All other chemicals used were analytical-reagent-grade (Purity $>99 \%$ ) and used as received.

\subsection{CNF Extraction and CNF Film Fabrication}

The CNF was extracted by the TEMPO oxidation and aqueous counter collision system (ACC, ACCNAC-100, CNNT, Suwon, Korea) combined method, which has been reported previously [40]. The TEMPO oxidation acts as a pretreatment process for the ACC process. In brief, the HW pulp was cut into small pieces and swelled in deionized (DI) water for one day before disintegrating by a food mixer for $10 \mathrm{~min}$. After that, TEMPO, NaBr, and DI water were added to the swollen HW pulp suspension. To start the oxidization process, the 
$\mathrm{NaClO}$ was added into the mixture and stirred at room temperature. A $\mathrm{pH}$ meter (Orion Star A211, Thermo Scientific, Waltham, MA, USA) was used to monitor the mixture's $\mathrm{pH}$ value, maintaining it at 12 by adding $\mathrm{NaOH}$. To stop the TEMPO oxidation reaction, $0.5 \mathrm{M}$ $\mathrm{HCl}$ was added into the mixture and adjusted the $\mathrm{pH}$ value to 7 . Finally, the oxidized cellulose pulp was washed with DI water to remove the chemical residues using a $90 \mu \mathrm{m}$ mesh sieve. The TEMPO-oxidized pulp was further pulverized using the ACC system. The pulp was passed through a pair of diamond nozzles in a collision chamber with $200 \mathrm{MPa}$, such that a pair of aqueous solution jets collide against each other, resulting in an aqueous CNF suspension. The number of ejections passing through the nozzles was called "pass" As the number of passes increases, the CNF size decreases. TEMPO oxidation $60 \mathrm{~min}$ and ACC 30-pass-treated CNF was an optimum condition from the previous research [40], and the same condition was used in this research. The CNF suspension was degassed using a centrifuge machine (Supra 22K, Hanil Scientific Inc., Incheon, Korea) with $5000 \mathrm{rpm}, 1 \mathrm{~h}$.

The CNF film was prepared using a doctor blade casting, as shown in Figure 1. A polycarbonate (PC) substrate was used for the CNF film casting. The PC substrate, where its boundaries were covered with the polyimide tape, was treated with an oxygen plasma using an oxygen-plasma treatment system (FEMTO Science, CUTE, Hwaseong-si, Korea) for $20 \mathrm{~s}$ to slightly increase its hydrophilicity of the PC substrate. The CNF suspension was cast on the plasma-treated PC plate using a doctor blade and dried in a cleanroom. After drying, the pristine CNF film was immersed in an ethanol bath for separating the pristine CNF film from the PC substrate. After evaporating ethanol, the pristine CNF film was peeled off from the PC substrate.

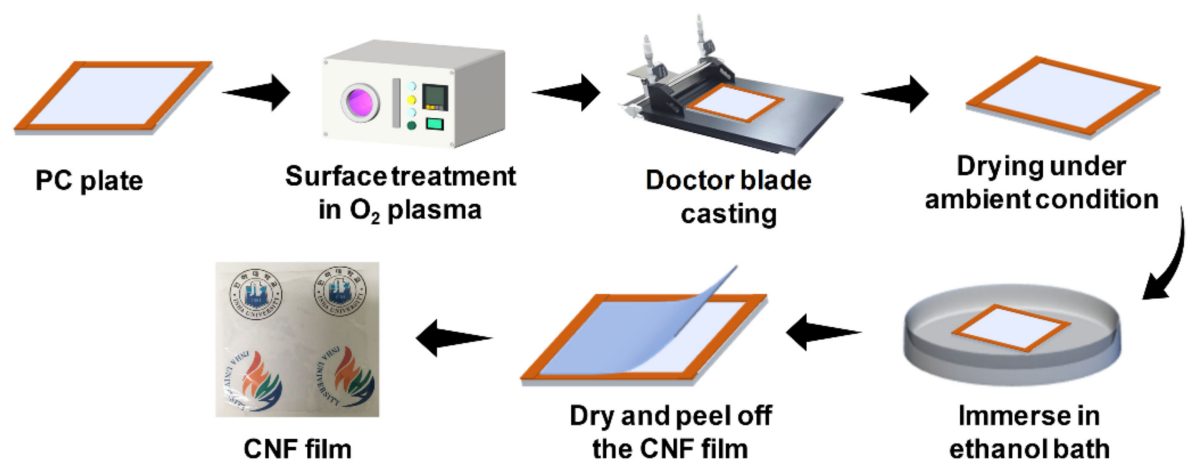

Figure 1. Schematic of CNF film fabrication process.

\subsection{ZnO-CNF Nanocomposite Fabrication}

The previously reported two-step process was adopted for growing $\mathrm{ZnO}$ nanorods on the CNF film: $\mathrm{ZnO}$ nanoparticles seeding and the $\mathrm{ZnO}$ nanorod growing [35]. In brief, the $\mathrm{CNF}$ film was fixed on a silicon wafer to maintain its flatness. Zinc acetate was dissolved in ethanol by stirring under $60^{\circ} \mathrm{C}$ for $1 \mathrm{~h}$, and the solution temperature was maintained at $60{ }^{\circ} \mathrm{C}$ to prevent $\mathrm{ZnO}$ crystal extraction. The solution was then spin-coated on the CNF film, followed by drying at $100^{\circ} \mathrm{C}$. This process was repeated 10 times with 3 min duration to form a dense $\mathrm{ZnO}$ seeding layer on top of the CNF film. After that, the ZnO-seeded CNF film was annealed at $100{ }^{\circ} \mathrm{C}$ for $30 \mathrm{~min}$. Figure 2a shows the $\mathrm{ZnO}$ seeding process.

For growing $\mathrm{ZnO}$ nanorods, zinc nitrate aqueous solution and HMT aqueous solution were mixed. After the $\mathrm{ZnO}$-seeded CNF film was floated on the surface of zinc nitrate aqueous solution, the solution was heated up to $90{ }^{\circ} \mathrm{C}$ for $1 \mathrm{~h}$. As the nanorods grew, the CNF film color was changed from transparent to hazy then perfectly white. After growing $\mathrm{ZnO}$ nanorods, the nanocomposite was dried at room temperature. By controlling the chemical concentration, $25 \mathrm{mM}$ and $50 \mathrm{mM}$ of $\mathrm{ZnO}$ growing solutions were used to fabricate two ZCNs: $25 \mathrm{mM}$ ZCN and 50mM ZCN. Figure $2 \mathrm{~b}$ shows the schematic of the $\mathrm{ZCN}$ fabrication process. 


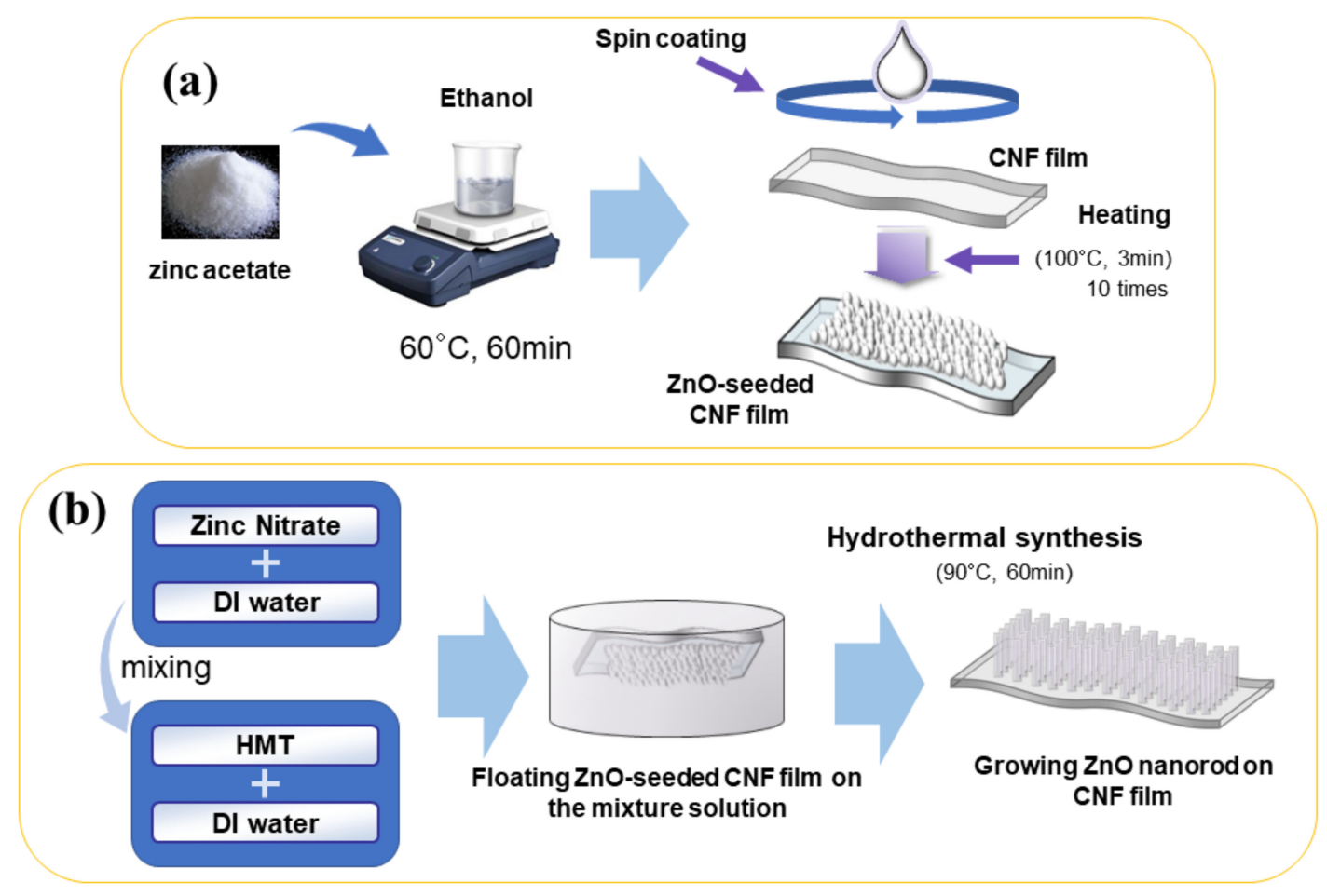

Figure 2. Schematic of $\mathrm{ZnO}-\mathrm{CNF}$ nanocomposite fabrication process: (a) seeding process and (b) nanorod growing process.

\subsection{Characterizations}

A UV-2501PC UV-Vis spectrometer (Shimadzu, Kyoto, Japan) was used to analyze the transparency of the pristine CNF film and ZCNs. Field-emission scanning electron microscopy (FESEM) (S-4000, Hitachi, Matsuda, Japan) was used to investigate the morphologies of the pristine CNF film and ZCNs.

The mechanical and electromechanical properties were measured using a tensile test system, which consists of a load cell (UU-K010, Dacell, Nami-Myeon, Korea), a servo motor controller, a picoammeter (Keithley 6485, Tektronix, Beaverton, OR, USA), an environmental chamber, and LabVIEW software (National Instruments, Austin, TX, USA)) with a personal computer [41]. Aluminum electrodes were deposited on both sides of specimens by a thermal evaporation system (SHE-6D-350T, Samhan, Paju, Korea). Thin copper wires were connected to the electrodes and grounded to release space charges accumulated on the electrodes during the deposition. The electromechanical property was found by measuring the piezoelectric charge constant, $\mathrm{d}_{31}$, in the tensile test system. The specimens were subjected to a tensile load in its length direction, and the induced current was measured across the thickness direction from the electrodes using the picoammeter. The induced current can be converted into a charge per unit electrode area, and $\mathrm{d}_{31}$ can be obtained as:

$$
\mathrm{d}_{31}=\left(\frac{\partial \mathrm{D}_{3}}{\partial \mathrm{T}_{1}}\right)_{\mathrm{E}}=\frac{\text { Induced charge per unit electrod area }}{\text { Applied in }- \text { plane normal stress }}[\mathrm{C} / \mathrm{N}]
$$

\subsection{UV Sensing Test}

Figure 3a shows the schematic of UV sensing from ZCN. The ZCN was cut into $1.7 \times 1.7 \mathrm{~cm}^{2}$, and then platinum or indium tin oxide (ITO) was coated with $1.5 \times 1.5 \mathrm{~cm}^{2}$ size using a sputtering system (K575X, Quorum Technologies Ltd., Lewes, UK) to form electrodes on both side of the specimens. Thin copper wires were attached to both electrodes using a conductive silver paste and then coated with a thin laminate film to protect the $\mathrm{ZnO}$ layer. Before proceeding with the UV sensing test, the specimen was attached on a linear stage such that the distance between the UV light source and the specimen can be adjusted 
(see Figure 3b). A UV light lamp (PL-S 9W/2P BLB, Philips, Eindhoven, The Netherlands) of $365 \mathrm{~nm}$ wavelength was used as the light source. The UV irradiance intensity was measured using a UV meter (UV-A Meter, Kuhnast, Wächtersbach, Germany), which has the highest sensitivity at $360 \mathrm{~nm}$ wavelength. UV irradiance intensities of 1, 1.5, 3, and $5 \mathrm{~mW} / \mathrm{cm}^{2}$ were applied to the specimens. For evaluating the UV sensing performance, the induced current was measured using the picoammeter. The UV irradiance was exposed to the cellulose side and $\mathrm{ZnO}$ side, and the exposure side effect was also investigated.
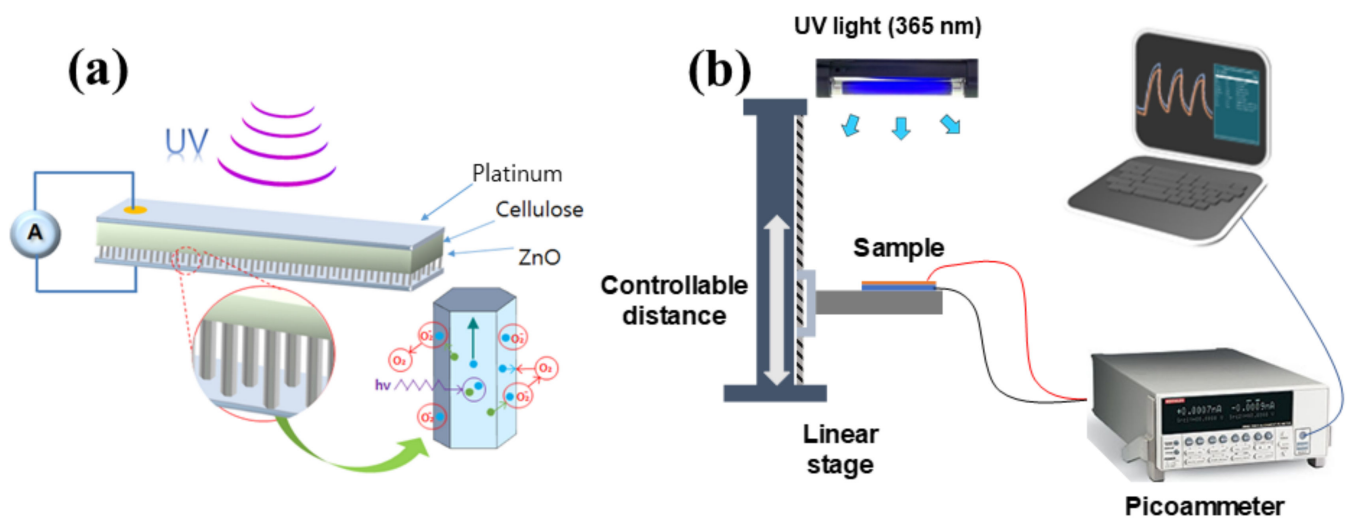

Figure 3. (a) Schematic of UV sensing ZCN and (b) UV-sensing test setup.

\section{Results}

\subsection{Optical Transparencies and Morphologies}

Figure 4 shows the transparency of the prepared ZCNs and the pristine CNF film. The pristine CNF film showed the highest transparency of $89.2 \%$ in the visible light range, and the ZCNs exhibited high transparencies of $82.9 \%$ and $80.7 \%$ for the $25 \mathrm{mM}$ and $50 \mathrm{mM} \mathrm{ZnO}$ concentrations. Within the UV wavelength range up to $370 \mathrm{~nm}$, the ZCNs mostly block UV light, indicating that the $\mathrm{ZnO}$ nanorods adsorb most UV lights.

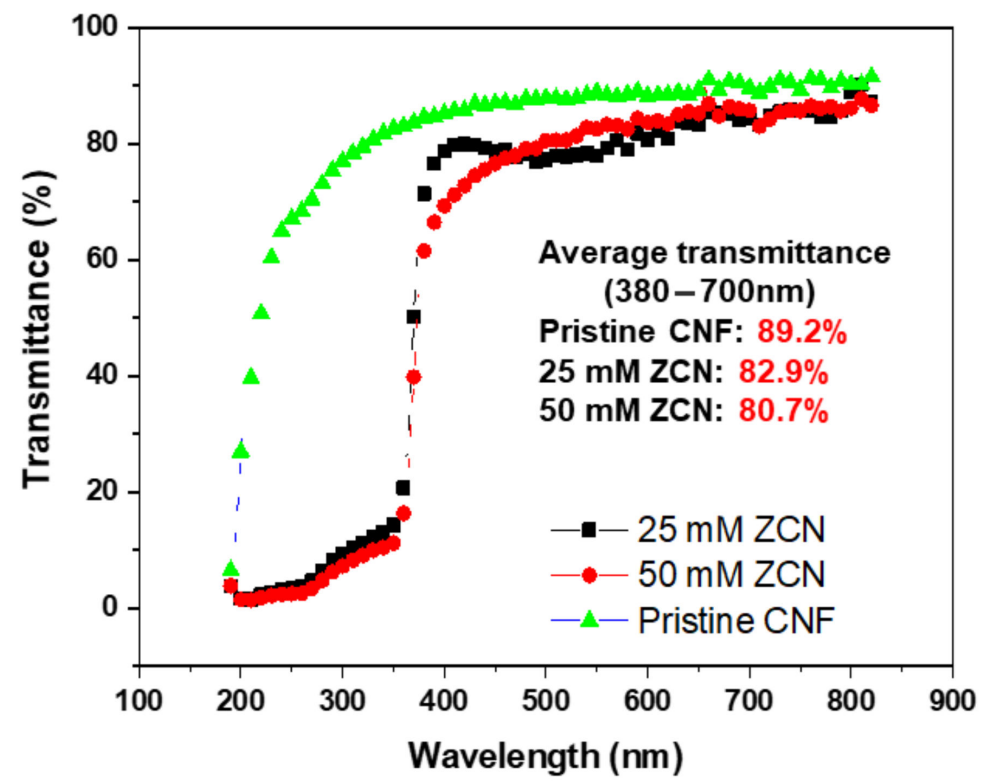

Figure 4. Optical transparencies of the pristine CNF film and ZnO-CNF nanocomposites.

Figure 5 shows the surface and cross-sectional morphologies of the pristine CNF film and ZCNs. The pristine CNF film surface is very smooth, and its cross-section exhibits a layered structure similar to the regenerated cellulose [42]. The $\mathrm{ZnO}$ nanorods were successfully grown vertically from the surface of CNF film, and their lengths of the $25 \mathrm{mM}$ 
and $50 \mathrm{mM}$ specimens are $500 \mathrm{~nm}$ and $800 \mathrm{~nm}$. The vertically grown $\mathrm{ZnO}$ nanorods are beneficial for improving optical transparency and electromechanical properties. The $\mathrm{ZnO}$ nanorod morphologies are similar to the previous report [35]. The $\mathrm{ZnO}$ nanorod diameter was similar to the previous result, $110 \mathrm{~nm}$ [35]. Lower optical transparency of the $50 \mathrm{mM}$ $\mathrm{ZCN}$ was attributed to the longer $\mathrm{ZnO}$ nanorods than the $25 \mathrm{mM} \mathrm{ZCN}$.

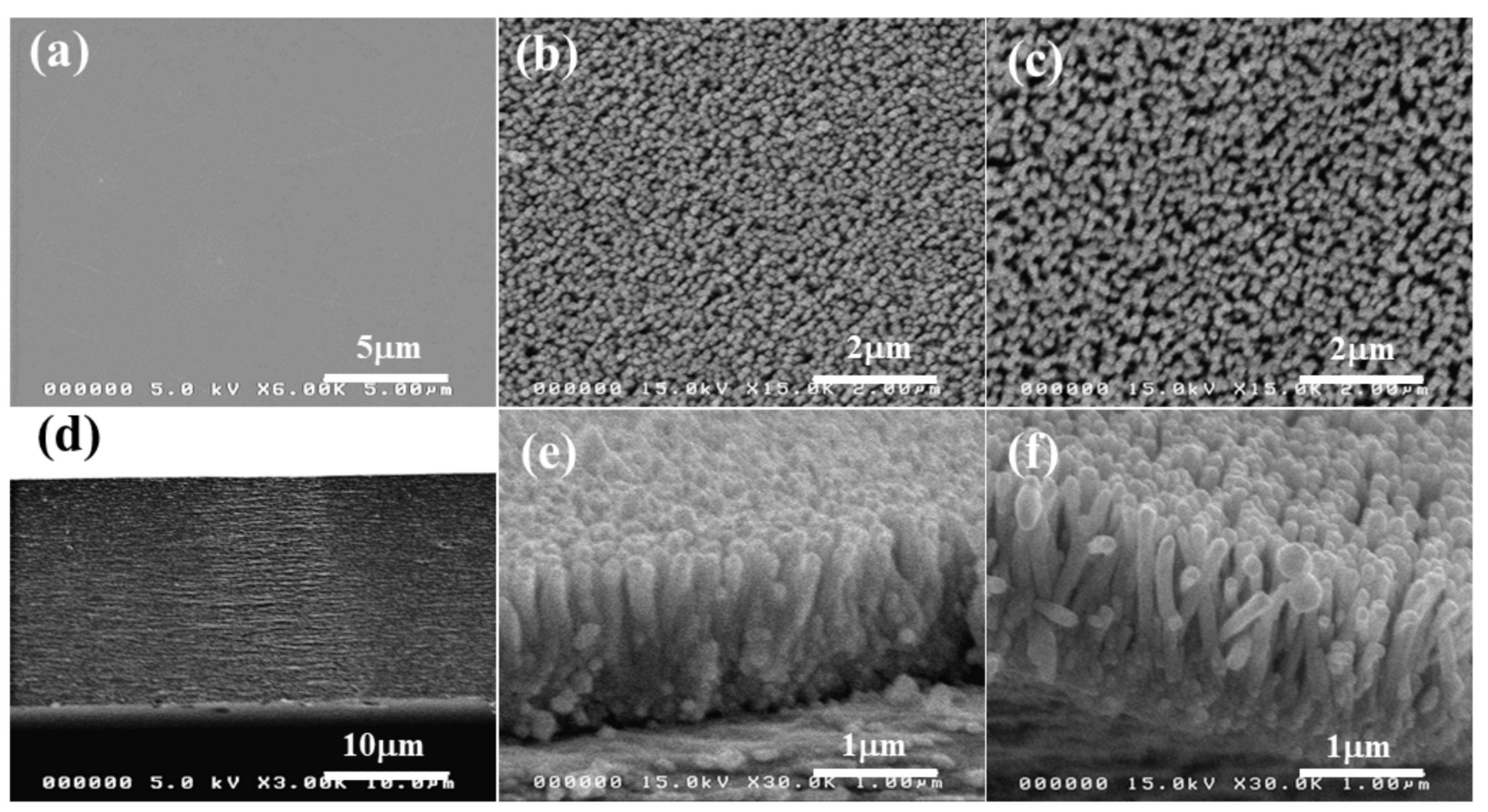

Figure 5. Surface $(\mathbf{a}-\mathbf{c})$ and cross-sectional $(\mathbf{d}-\mathbf{f})$ FESEM images: (a,d) the pristine CNF film, $(\mathbf{b}, \mathbf{e}) 25 \mathrm{mM} Z \mathrm{ZCN}$, (c,f) $50 \mathrm{mM} \mathrm{ZCN}$.

\subsection{Mechanical and Electromechanical Properties}

The mechanical and electromechanical properties of the pristine CNF and ZCNs were measured. Figure 6a shows the stress-strain curves of the specimens. The yielding occurred around $0.8-1.2 \%$ strain, and by fitting the slopes of the stress-strain curves within the elastic region, Young's moduli were found. The results are listed in Table 1. The tensile strength (St) of the pristine CNF film was $131.4 \mathrm{MPa}$, which is a bit larger than the regenerated cellulose film (120 MPa, no-stretching) [42]. The Young's modulus of the pristine CNF film was $12.8 \mathrm{GPa}$, much larger than the regenerated cellulose film (5.3 GPa, no-stretching). The CNF pristine film's mechanical properties increase might be associated with the CNF alignment in the pristine CNF film. Thus, it is beneficial to use the pristine CNF film instead of the regenerated cellulose film for the ZCN.

After $\mathrm{ZnO}$ nanorod growing, the tensile strength of $\mathrm{ZCNs}$ ranged $115-116 \mathrm{MPa}$, and Young's modulus was in the range of 9.6-9.7 GPa, a bit less than the pristine CNF film. The decreased mechanical properties might be due to the material mismatch between the $\mathrm{CNF}$ film and the grown $\mathrm{ZnO}$ nanorods. Note that the thickness of the $\mathrm{ZnO}$ nanorod layers was $0.5-0.8 \mu \mathrm{m}$, and the CNF film thickness was $20 \mu \mathrm{m}$. The grown $\mathrm{ZnO}$ nanorods cannot resist under the tensile load because they were grown perpendicular to the CNF film. Thus, although the $\mathrm{ZnO}$ layer thickness was smaller than the CNF film, the overall mechanical properties of $\mathrm{ZCN}$ were decreased. 

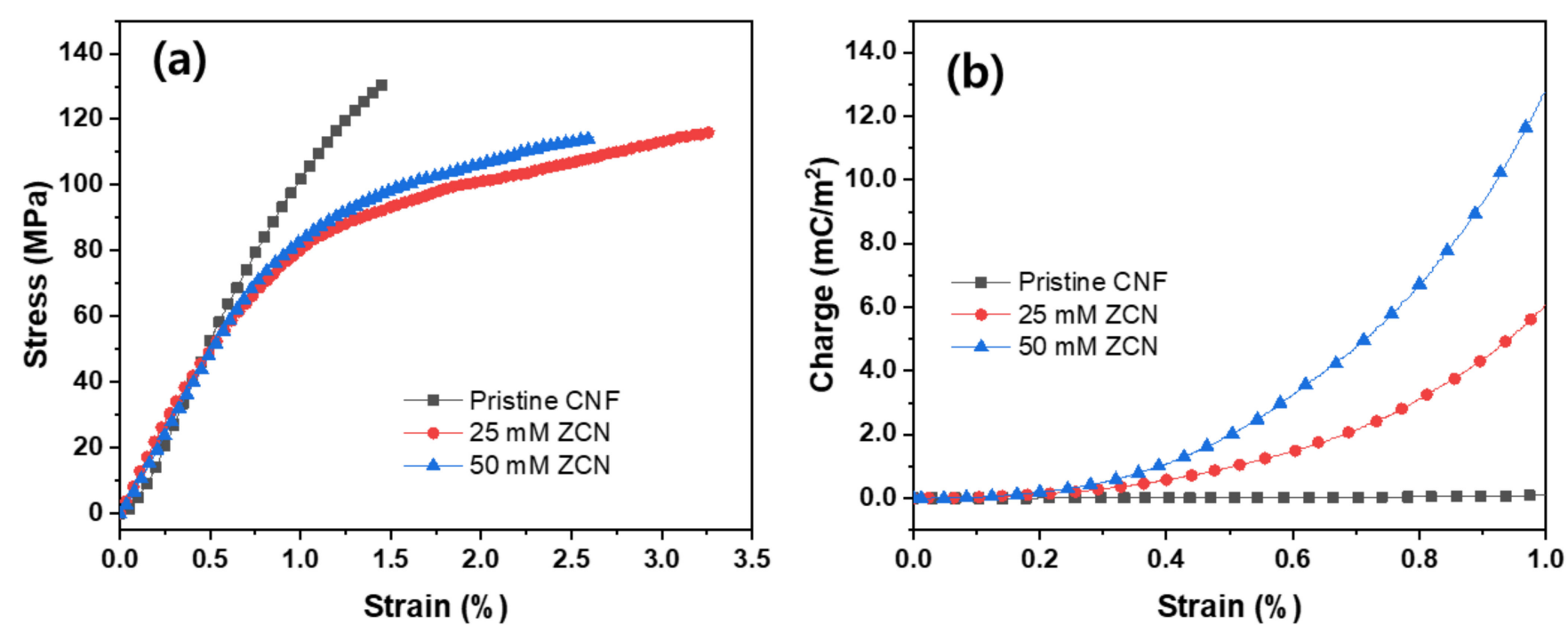

Figure 6. (a) Stress-strain curves and (b) induced charge curves of the pristine CNF film and ZCNs.

Table 1. Mechanical and electromechanical properties of the pristine CNF and ZCNs.

\begin{tabular}{cccc}
\hline Sample & E (GPa) & St $\mathbf{~ M P a )}$ & $\mathbf{d}_{\mathbf{3 1}}(\mathbf{p C} / \mathbf{N})$ \\
\hline Pristine CNF film & $12.8 \pm 0.1$ & $131.4 \pm 3.7$ & $0.22 \pm 0.1$ \\
25 mM ZCN & $9.6 \pm 1.4$ & $116.0 \pm 12$ & $26 \pm 5.6$ \\
$50 \mathrm{mM}$ ZCN & $9.7 \pm 0.3$ & $115.0 \pm 13.7$ & $48.8 \pm 11.7$ \\
\hline $\begin{array}{c}\text { Regenerated cellulose } \\
\text { EAPap [36] }\end{array}$ & 5.3 & 120 & 3.4 \\
\hline
\end{tabular}

Figure $6 \mathrm{~b}$ shows the charge-strain curves of the pristine CNF film and ZCNs. Straininduced charges increased with increasing the $\mathrm{ZnO}$ concentration within the elastic region. The piezoelectric charge constant, $\mathrm{d}_{31}$, of the pristine $\mathrm{CNF}$ film was $0.22 \mathrm{pC} / \mathrm{N}$. This value is lower than the regenerated-cellulose electro-active paper (EAPap) without stretching, $3.4 \mathrm{pC} / \mathrm{N}$ [42]. Note that the $\mathrm{d}_{31}$ of the regenerated cellulose EAPap drastically increased up to $16-17 \mathrm{pC} / \mathrm{N}$ as the stretching ratio increased to $2.0[42,43]$. The $\mathrm{d}_{31}$ values of the $25 \mathrm{mM}$ and $50 \mathrm{mM} Z \mathrm{ZCNs}$ were 26 and $48.8 \mathrm{pC} / \mathrm{N}$. The maximum $\mathrm{d}_{31}$ of the $50 \mathrm{mM} \mathrm{ZCN}$ is 14 times larger than the regenerated cellulose EAPap, and 200 times larger than the pristine CNF film. The remarkable electromechanical property is attributed to the dipolar orientation of $\mathrm{ZnO}$ nanorods and surface piezoelectricity between the CNF film and the $\mathrm{ZnO}$ nanorods.

\subsection{UV Sensing Test}

The prepared ZCNs were UV-sensing-tested. The $\mathrm{ZnO}$ concentration effect on the UV sensing was investigated. Figure 7 shows the induced current from the ZCNs depending on the $\mathrm{ZnO}$ concentration when the UV light was on and off under $5 \mathrm{~mW} / \mathrm{cm}^{2} \mathrm{UV}$ irradiance. As the UV light was on, the current output from ZCNs sharply increased and saturated within 20-30 s. The $50 \mathrm{mM} \mathrm{ZCN}$, however, gradually decreased after the saturation. After the UV light was off, the current output of ZCNs immediately decreased and returned to the nearly initial level after $120 \mathrm{~s}$. Note that the current outputs are repeatable. The $50 \mathrm{mM}$ ZCN exhibited almost four times higher current output than the $25 \mathrm{mM} \mathrm{ZCN}$, which might be associated with the $\mathrm{ZnO}$ nanorods' length. Since bigger $\mathrm{ZnO}$ nanorods in the $50 \mathrm{mM}$ $\mathrm{ZCN}(800 \mathrm{~nm})$ than the $25 \mathrm{mM} \mathrm{ZCN}(500 \mathrm{~nm})$ give a larger surface area, more oxygen molecules can be attracted on the $\mathrm{ZnO}$ nanorods, such that larger current output can be obtained from the $50 \mathrm{mM} \mathrm{ZCN}$ than the $25 \mathrm{mM} \mathrm{ZCN}$. 


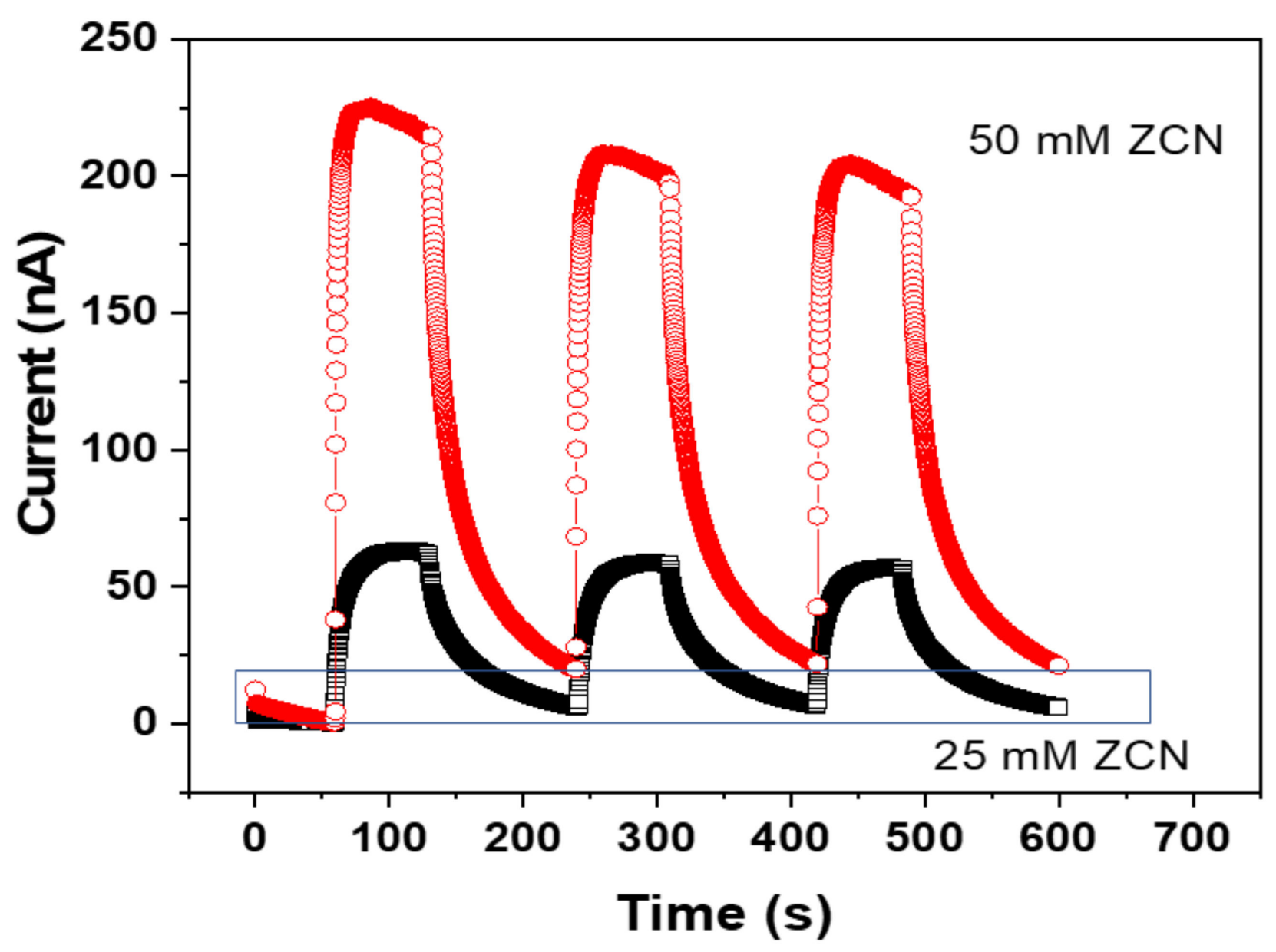

Figure 7. Induced current outputs of $\mathrm{ZCNs}$ with different $\mathrm{ZnO}$ concentrations.

Figure 8a,b show the induced current outputs of ZCNs under the UV irradiance change. By controlling the distance between the UV light source and the specimens, the UV irradiance intensity was measured using the UV-A meter, and the intensity levels were $1,1.5,3$, and $5 \mathrm{~mW} / \mathrm{cm}^{2}$. Both $25 \mathrm{mM}$ and $50 \mathrm{mM} \mathrm{ZCNs}$ were tested under the same condition. As the UV irradiance turned on and off with increasing the UV irradiance intensity, the current outputs followed the intensity signals and the maximum current outputs increased. Figure $8 \mathrm{c}$ shows the maximum current outputs of ZCNs with the UV irradiance change. The $25 \mathrm{mM} Z \mathrm{ZCN}$ exhibited a linear response, whereas the $50 \mathrm{mM} \mathrm{ZCN}$ represented a nonlinear response, which might be due to its large current output.

Since the ZCN has two different sides, the UV exposure side effect was investigated by irradiating UV light onto the $\mathrm{ZnO}$ nanorods side and cellulose side. Figure 9 represents the induced current outputs of ZCNs by exposing UV irradiance to $\mathrm{ZnO}$ nanorods side and cellulose side for the $25 \mathrm{mM} \mathrm{ZCN} \mathrm{(a)} \mathrm{and} 50 \mathrm{mM} \mathrm{ZCN} \mathrm{(b).} \mathrm{The} \mathrm{test} \mathrm{was} \mathrm{performed}$ under $3 \mathrm{~mW} / \mathrm{cm}^{2} \mathrm{UV}$ irradiance intensity. In the $25 \mathrm{mM} \mathrm{ZCN}$, the current output from the cellulose side was slightly larger than the $\mathrm{ZnO}$ nanorods side. However, the $50 \mathrm{mM}$ ZCN was different: the current output from the cellulose side was almost twice higher than the $\mathrm{ZnO}$ nanorods side. The CNF film is transparent, and the interface boundary between the $\mathrm{CNF}$ film and the $\mathrm{ZnO}$ seed layer is smoother than the $\mathrm{ZnO}$ nanorods side. The cellulose side scattered the UV irradiance less than the $\mathrm{ZnO}$ nanorods side, such that more current output occurred from the cellulose-side exposure [35]. 

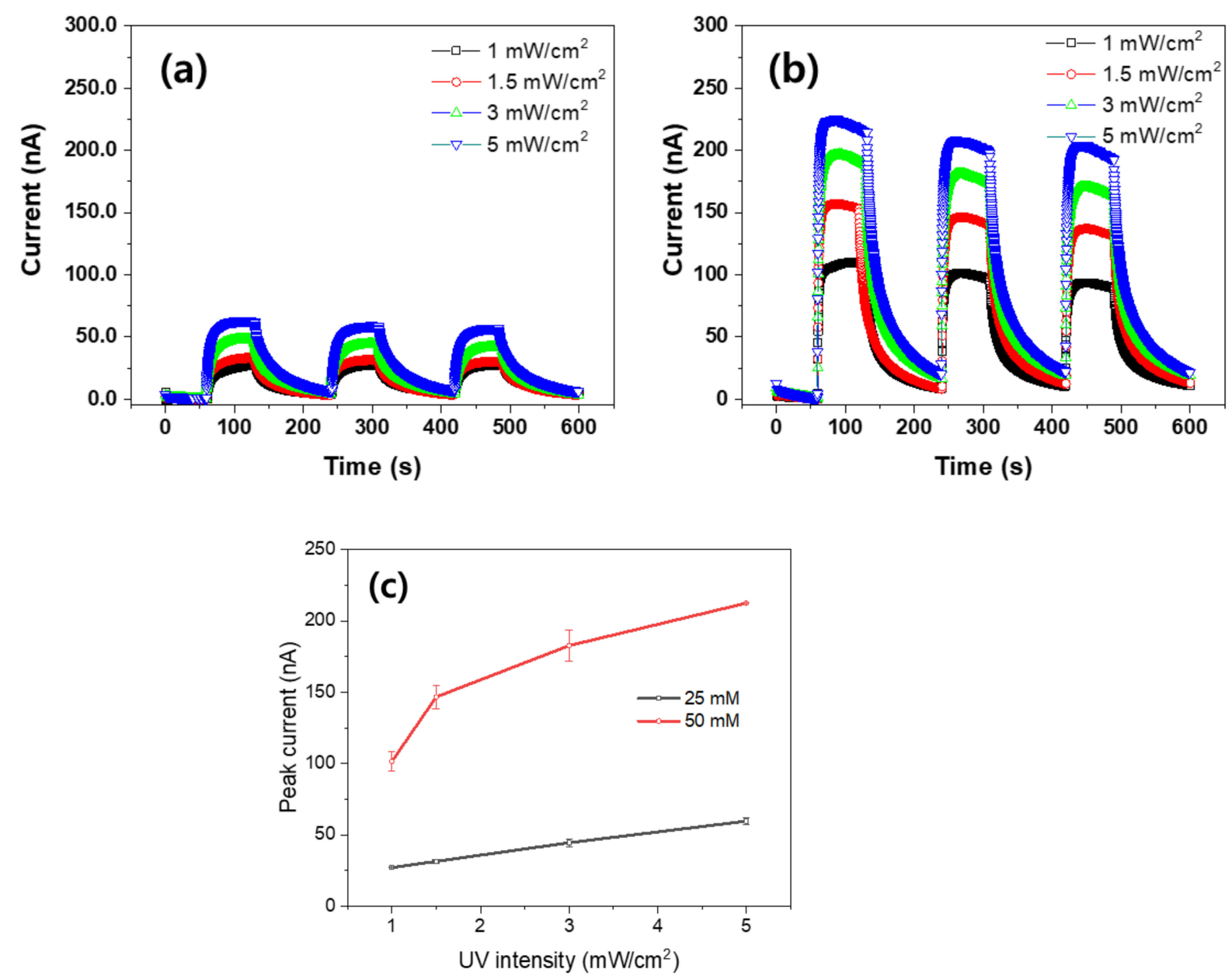

Figure 8. Induced current outputs of ZCNs: (a) $25 \mathrm{mM} \mathrm{ZCN,} \mathrm{(b)} 50 \mathrm{mM} \mathrm{ZCN}$, and (c) the UV irradiance intensity effect.
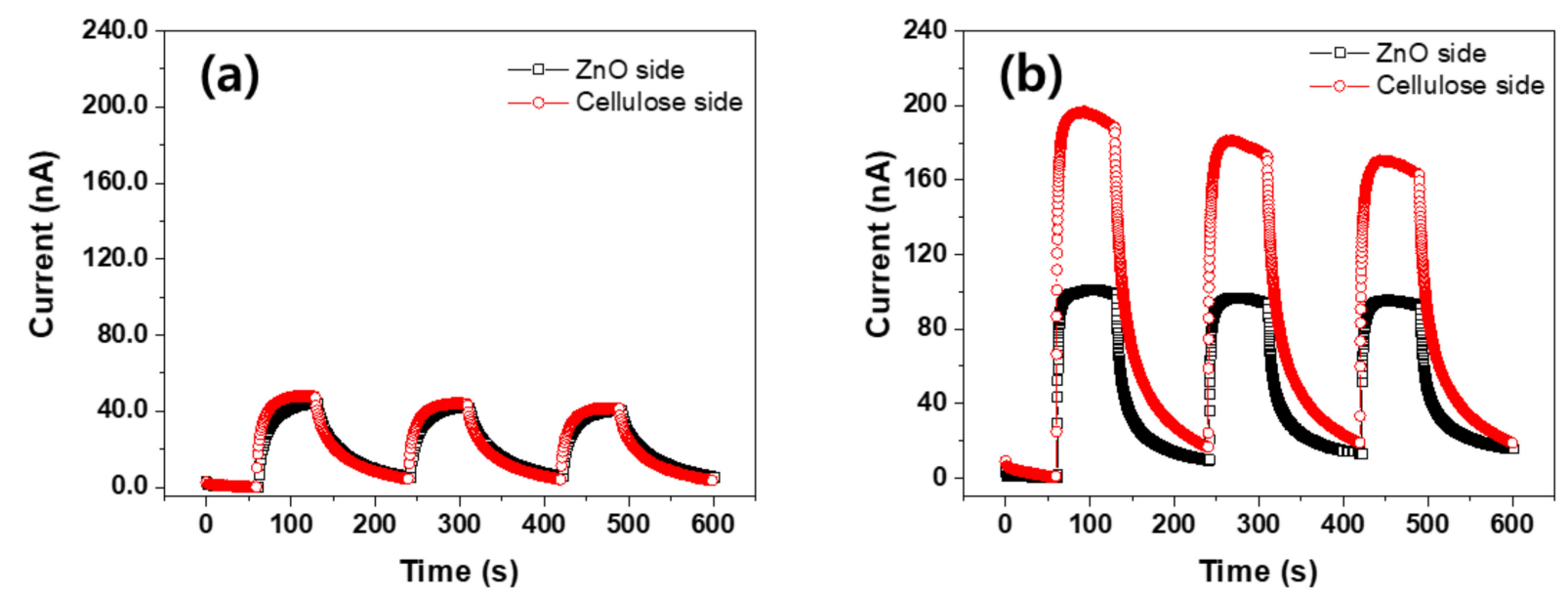

Figure 9. Current outputs of ZCNs with different UV irradiate sides: (a) $25 \mathrm{mM} Z \mathrm{ZCN}$ and (b) $50 \mathrm{mM}$ ZCN.

So far, Pt was coated on both sides of ZCNs to form electrodes. To investigate the electrode material effect on the UV sensing performance, a transparent electrode material, ITO, was coated on both sides of the ZCNs and compared with the Pt electrode. Figure 10 shows the current output of the $25 \mathrm{mM} \mathrm{ZCN} \mathrm{(a)} \mathrm{and} \mathrm{the} 50 \mathrm{mM} \mathrm{ZCN} \mathrm{(b)} \mathrm{for} \mathrm{both} \mathrm{electrode}$ materials. Inset photographs show the images of the Pt- and ITO-coated ZCNs. Note that ITO is known to be transparent at $365 \mathrm{~nm}$ in contrast to Pt. Thus the ITO-coated 
$\mathrm{ZCN}$ is beneficial for achieving a transparent UV sensor. The Pt electrode ones showed larger current output than the ITO electrode cases in $25 \mathrm{mM}$ and $50 \mathrm{mM}$ ZCNs. The Pt-electrode-induced current was 1.8 times larger than the ITO electrode, and the $50 \mathrm{mM}$ $\mathrm{ZCN}$ was 3 times larger. This phenomenon might be associated with the work function difference between the electrode and $\mathrm{ZnO}$ nanorods: $\mathrm{ZnO}$ work function is $4.3 \mathrm{eV}, \mathrm{Pt}$ is $5.7 \mathrm{eV}$, and ITO is around $4.3 \mathrm{eV}$ [44]. The large work function gap between the $\mathrm{ZnO}$ and the electrode induced high current output under the same UV irradiance intensity. Since the work function of ITO electrode is almost the same as the $\mathrm{ZnO}$, the ITO electrode did not show large current outputs. The Pt electrode on the $\mathrm{ZnO}$ nanorods could correspond to Schottky contact, which results in a large forward current and very low reverse bias. Additionally, the conductivity of the ITO electrode is lower than the Pt electrode. Note that the ITO electrode's current outputs dropped quickly after turning on the UV light. It might be because the oxygen atoms incorporated into the ITO electrode decrease the oxygen vacancies and then give rise to the ITO electrode's high resistivity, which resulted in fast current decay.
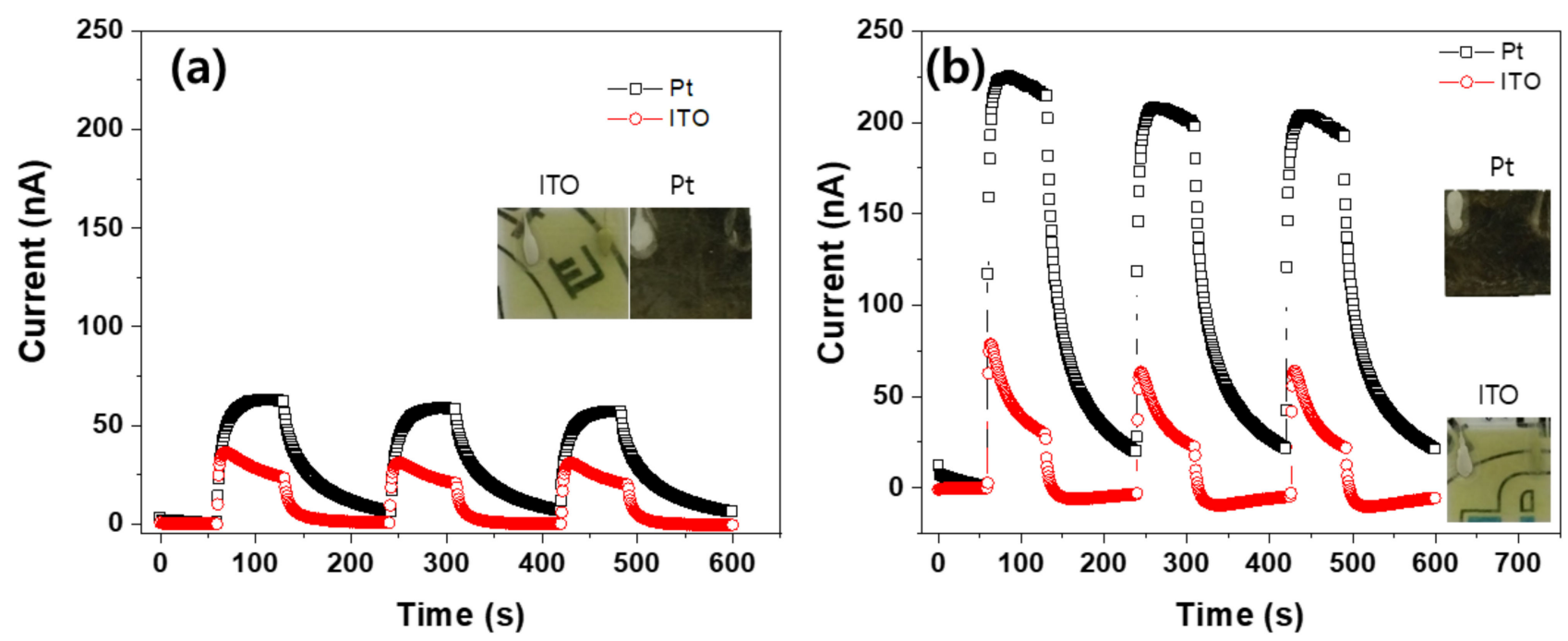

Figure 10. Platinum and ITO electrodes' effect on the ZCN: (a) $25 \mathrm{mM} \mathrm{ZCN}$ and (b) $50 \mathrm{mM} \mathrm{ZCN}$.

The UV sensing performance of $\mathrm{ZCN}$ was compared with the previously reported cellulose-ZnO hybrid nanocomposite (CEZOHN) [35]. CEZOHN is a ZnO-nanorod hybrid nanocomposite grown on a regenerated cellulose film. Figure 11a shows the peak current outputs of the ZCNs compared with the CEZOHN as the UV irradiation intensity changes. The current outputs were normalized with the electrode areas, and the ZCNs were recapped from Figure 8c. The peak current outputs increased with the UV irradiation intensity, and the CEZOHN exhibited higher UV sensing performance than the ZCNs. The high performance of UV sensing was investigated with the $\mathrm{ZnO}$ nanorod length. The ZCNs used the same $\mathrm{ZnO}$ seeding and growing process as the CEZOHN. Note that the CEZOHN used a $50 \mathrm{mM}$ concentration of zinc nitrate aqueous solution for growing the $\mathrm{ZnO}$ nanorods. Figure $11 \mathrm{~b}$ represents the unit current output of ZCNs and CEZOHN with the length of the nanorods. The unit current output was calculated from the maximum peak current outputs divided by the UV irradiation intensity, which turned out to be $\mathrm{nA} / \mathrm{mW}$. The $\mathrm{ZnO}$ nanorods' length of CEZOHN was $1 \mu \mathrm{m}$, and the ZC was $500 \mathrm{~nm}$ and $800 \mathrm{~nm}$. Table 2 represents the photosensitivities of the prepared ZCNs comparing with CEZOHN. The peak current increased from $59.69 \pm 2.57$ to $212.53 \pm 9.09 \mathrm{nA}$ for the $25 \mathrm{mM}$ and $50 \mathrm{mM}$ ZCNs, and their unit current output increased from $11.94 \pm 0.51$ to $42.51 \pm 1.82 \mathrm{nA} / \mathrm{mW} / \mathrm{cm}^{2}$. It is clearly shown that the current output is strongly related to the $\mathrm{ZnO}$ nanorods' length. Thus, a large aspect ratio of $\mathrm{ZnO}$ nanorods is crucial for improving the UV sensing performance. A significant work function difference between $\mathrm{ZnO}$ nanorods and the electrode 
material should be made for performance improvement. However, the large aspect ratio of $\mathrm{ZnO}$ nanorods and considerable work function electrode material could deteriorate the ZCN's transparency. Thus, they should be compromised with the transparency of ZCN. Nevertheless, the use of CNF for ZCN is beneficial for high mechanical properties, renewability, biocompatibility, flexibility, non-toxicity, and transparency.
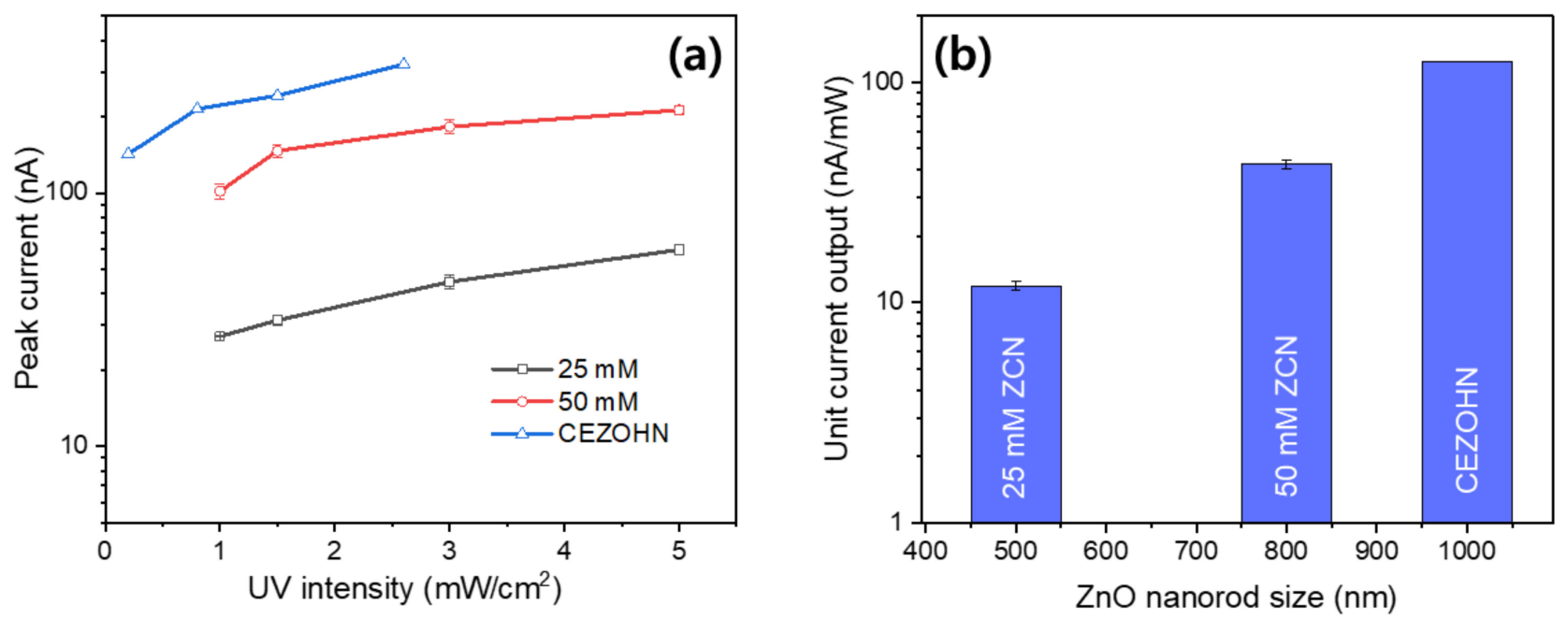

Figure 11. Current output comparison of ZCNs and CEZOHN: (a) peak current outputs with UV intensity changing and (b) the maximum unit current output with the $\mathrm{ZnO}$ nanorods' length.

Table 2. Photosensitivities of the ZCNs compared with CEZOHN.

\begin{tabular}{|c|c|c|c|}
\hline \multirow{2}{*}{ Sample } & \multicolumn{2}{|c|}{ ZCNs } & \multirow{2}{*}{ CEZOHN } \\
\hline & $25 \mathrm{mM} \mathrm{ZCN}$ & $50 \mathrm{mM} \mathrm{ZCN}$ & \\
\hline Peak current $\left(\mathrm{nA} / \mathrm{cm}^{2}\right)$ & $59.69 \pm 2.57$ & $212.53 \pm 9.09$ & 142.5 \\
\hline $\begin{array}{l}\text { Unit current output } \\
\left(\mathrm{nA} / \mathrm{mW} / \mathrm{cm}^{2}\right)\end{array}$ & $11.94 \pm 0.51$ & $42.51 \pm 1.82$ & 124.0 \\
\hline $\mathrm{ZnO}$ nanorod size $(\mathrm{nm})$ & 500 & 800 & 1000 \\
\hline Response time (s) & 70 & 35 & 25 \\
\hline
\end{tabular}

\section{Conclusions}

In this study, the environment-friendly $\mathrm{ZnO}-\mathrm{CNF}$ nanocomposites were fabricated by growing $\mathrm{ZnO}$ nanorods on the CNF film using two-step methods: seeding and nanorod growing by the hydrothermal method. The CNF extraction, the film casting, the $\mathrm{ZnO}$ nanorod growing, and all characterization were performed. The tensile strength and Young's modulus of the CNF film (120 MPa, 12.8 GPa) were higher than the regenerated cellulose film (120 MPa, 5.3 GPa). Thus, it is beneficial to use the CNF film instead of the regenerated cellulose film to form the nanocomposites. Transparency of the $\mathrm{ZnO}-\mathrm{CNF}$ nanocomposites slightly decreased from the pristine CNF film but still maintained more than $80 \%$. The SEM images exhibited that the $\mathrm{ZnO}$ nanorods were grown uniformly on the CNF film surface, and the length of the nanorods was $500 \mathrm{~nm}$ and $800 \mathrm{~nm}$ for $25 \mathrm{mM}$ and $50 \mathrm{mM} \mathrm{ZnO}$ concentration nanocomposites. After growing $\mathrm{ZnO}$ nanorods on the CNF film, the electromechanical property was increased more than 200 times compared to the pristine $\mathrm{CNF}$ film. As the $\mathrm{ZnO}$ concentration increased, the electromechanical property increased.

The UV sensing performance of the prepared $\mathrm{ZnO}-\mathrm{CNF}$ nanocomposites was tested in terms of $\mathrm{ZnO}$ concentration, UV irradiance intensity, exposure side, and electrode materials. When increasing the $\mathrm{ZnO}$ concentration and UV irradiance intensity, the induced current output also increased. When the cellulose side was exposed to the UV irradiance, the induced current was higher than the $\mathrm{ZnO}$ nanorods-side exposure. Due to the transparency 
and smooth surface of the CNF film, it scattered UV irradiance less than the $\mathrm{ZnO}$ nanorods side. Regarding the electrode materials, the Pt electrode generated larger current output than the ITO electrode, which is associated with the work function difference between the electrode material and the $\mathrm{ZnO}$ nanorods.

The UV sensing performance of the $\mathrm{ZnO}-\mathrm{CNF}$ nanocomposite and the previously reported regenerated cellulose-based $\mathrm{ZnO}$ hybrid nanocomposite was compared. The current output from the regenerated cellulose-based one was higher than the $\mathrm{ZnO}-\mathrm{CNF}$ nanocomposites, attributed to the $\mathrm{ZnO}$ nanorods' length. When increasing the length of the nanorods, the current output also increased. The high aspect ratio of $\mathrm{ZnO}$ nanorods in conjunction with the work function gap between $\mathrm{ZnO}$ nanorods and the electrode material are essential to improve the UV sensing performance, although they should be compromised with the transparency. The use of CNF for $\mathrm{ZnO}$-cellulose hybrid nanocomposites is beneficial not only for electromechanical and UV sensing properties but also for high mechanical properties, renewability, biocompatibility, flexibility, non-toxicity, and transparency.

Author Contributions: Conceptualization, L.Z. and J.K.; Data curation and experiments, R.M.M. and H.-C.K.; Writing—original draft preparation, L.Z.; Visualization, R.M.M. and M.L.; Writingreview and editing, H.A., R.A.M. and J.K.; Supervision, J.K. All authors have read and agreed to the published version of the manuscript.

Funding: This study was supported by the Deanship of Scientific Research at Prince Sattam Bin Abdulaziz University under research project no. 2020/1/17063.

Institutional Review Board Statement: Not applicable.

Informed Consent Statement: Not applicable.

Data Availability Statement: The data presented in this study are available on request from the corresponding author.

Conflicts of Interest: The authors declare no conflict of interest.

\section{References}

1. Tressler, J.F.; Alkoy, S.; Dogan, A.; Newnham, R.E. Functional composites for sensors, actuators and transducers. Compos. Part. A Appl. Sci. Manuf. 1999, 30, 477-482. [CrossRef]

2. Marchessault, R.H.; Liang, C.Y. Infrared spectra of crystalline polysaccharides. III. Mercerized cellulose. J. Polym. Sci. 1960, 43, 71-84. [CrossRef]

3. Moon, R.J.; Martini, A.; Nairn, J.; Simonsen, J.; Youngblood, J. Cellulose nanomaterials review: Structure, properties and nanocomposites. Chem. Soc. Rev. 2011, 40, 3941-3994. [CrossRef]

4. Klemm, D.; Kramer, F.; Moritz, S.; Lindström, T.; Ankerfors, M.; Gray, D.; Dorris, A. Nanocelluloses: A new family of nature-based materials. Angew. Chem. Int. Ed. 2011, 50, 5438-5466. [CrossRef]

5. Mokhena, T.C.; John, M.J. Cellulose nanomaterials: New generation materials for solving global issues. Cellulose 2020, 27, 1149-1194. [CrossRef]

6. Dufresne, A. Nanocellulose: A new ageless bionanomaterial. Mater. Today 2013, 16, 220-227. [CrossRef]

7. Ray, U.; Zhu, S.; Pang, Z.; Li, T. Mechanics design in cellulose-enabled high-performance functional materials. Adv. Mater. 2020. [CrossRef]

8. Cherian, B.M.; Leão, A.L.; de Souza, S.F.; Costa, L.M.M.; de Olyveira, G.M.; Kottaisamy, M.; Nagarajan, E.R.; Thomas, S. Cellulose nanocomposites with nanofibres isolated from pineapple leaf fibers for medical applications. Carbohydr. Polym. 2011, 86, 1790-1798. [CrossRef]

9. Aulin, C.; Gällstedt, M.; Lindström, T. Oxygen and oil barrier properties of microfibrillated cellulose films and coatings. Cellulose 2010, 17, 559-574. [CrossRef]

10. Chen, J.; Huang, X.; Zhu, Y.; Jiang, P. Cellulose nanofiber supported 3D interconnected BN nanosheets for epoxy nanocomposites with ultrahigh thermal management capability. Adv. Funct. Mater. 2017, 27, 1604754. [CrossRef]

11. Kim, J.; Yun, S.; Ounaies, Z. Discovery of cellulose as a smart material. Macromolecules 2006, 39, 4202-4206. [CrossRef]

12. Kafy, A.; Sadasivuni, K.K.; Akther, A.; Min, S.-K.; Kim, J. Cellulose/graphene nanocomposite as multifunctional electronic and solvent sensor material. Mater. Lett. 2015, 159, 20-23. [CrossRef]

13. Kafy, A.; Sadasivuni, K.K.; Kim, H.-C.; Akther, A.; Kim, J. Designing flexible energy and memory storage materials using cellulose modified graphene oxide nanocomposites. Phys. Chem. Chem. Phys. 2015, 17, 5923-5931. [CrossRef] [PubMed] 
14. Gomez-Romero, P. Hybrid organic-inorganic materials-In search of synergic activity. Adv. Mater. 2001, 13, 163-174. [CrossRef]

15. Sanchez, C.; Julián, B.; Belleville, P.; Popall, M. Applications of hybrid organic-inorganic nanocomposites. J. Mater. Chem. 2005, 15, 3559-3592. [CrossRef]

16. Özgür, Ü.; Alivov, Y.I.; Liu, C.; Teke, A.; Reshchikov, M.A.; Doğan, S.; Avrutin, V.; Cho, S.-J.; Morkoç, H. A comprehensive review of $\mathrm{ZnO}$ materials and devices. J. Appl. Phys. 2005, 98, 041301. [CrossRef]

17. Jayadevan, K.P.; Tseng, T.Y. One-dimensional ZnO nanostructures. J. Nanosci. Nanotechnol. 2012, 12, 4409-4457. [CrossRef]

18. Wang, X.; Song, J.; Liu, J.; Wang, Z.L. Direct-current nanogenerator driven by ultrasonic waves. Science 2007, 316, 102-105. [CrossRef]

19. Chu, S.; Li, D.; Chang, P.-C.; Lu, J.G. Flexible dye-sensitized solar cell based on vertical ZnO nanowire arrays. Nanoscale Res. Lett. 2010, 6, 38. [CrossRef]

20. Yao, I.C.; Tseng, T.-Y.; Lin, P. ZnO nanorods grown on polymer substrates as UV photodetectors. Sens. Actuator A Phys. 2012, 178, 26-31. [CrossRef]

21. Nanto, H.; Minami, T.; Takata, S. Zinc-oxide thin-film ammonia gas sensors with high sensitivity and excellent selectivity. J. Appl. Phys. 1986, 60, 482-484. [CrossRef]

22. Swanwick, M.E.; Pfaendler, S.M.L.; Akinwande, A.I.; Flewitt, A.J. Near-ultraviolet zinc oxide nanowire sensor using low temperature hydrothermal growth. Nanotechnology 2012, 23, 344009. [CrossRef]

23. Park, T.; Kim, N.; Kim, D.; Kim, S.-W.; Oh, Y.; Yoo, J.-K.; You, J.; Um, M.-K. An organic/inorganic nanocomposite of cellulose nanofibers and $\mathrm{ZnO}$ nanorods for highly sensitive, reliable, wireless, and wearable multifunctional sensor applications. ACS Appl. Mater. Interfaces 2019, 11, 48239-48248. [CrossRef]

24. Rodwihok, C.; Choopun, S.; Ruankham, P.; Gardchareon, A.; Phadungdhitidhada, S.; Wongratanaphisan, D. UV sensing properties of ZnO nanowires/nanorods. Appl. Surf. Sci. 2019, 477, 159-165. [CrossRef]

25. Park, T.; Lee, K.E.; Kim, N.; Oh, Y.; Yoo, J.K.; Um, M.-K. Aspect ratio-controlled ZnO nanorods for highly sensitive wireless ultraviolet sensor applications. J. Mater. Chem. C 2017, 46, 12256-12263. [CrossRef]

26. Kar, J.P.; Das, S.N.; Choi, J.H.; Lee, Y.A.; Lee, T.Y.; Myoung, J.M. Fabrication of UV detectors based on ZnO nanowires using silicon microchannel. J. Cryst. Growth 2009, 311, 3305-3309. [CrossRef]

27. Khan, A.; Hussain, M.; Nur, O.; Willander, M. Mechanical and piezoelectric properties of zinc oxide nanorods grown on conductive textile fabric as an alternative substrate. J. Phys. D Appl. Phys. 2014, 47, 345102. [CrossRef]

28. Zhou, Z.; Zhao, Y.; Cai, Z. Low-temperature growth of ZnO nanorods on PET fabrics with two-step hydrothermal method. Appl. Surf. Sci. 2010, 256, 4724-4728. [CrossRef]

29. Ladanov, M.; Ram, M.K.; Matthews, G.; Kumar, A. Structure and opto-electrochemical properties of ZnO nanowires grown on n-Si substrate. Langmuir 2011, 27, 9012-9017. [CrossRef] [PubMed]

30. Asib, N.A.M.; Husairi, F.S.; Eswar, K.A.; Afaah, A.N.; Mamat, M.H.; Rusop, M.; Khusaimi, Z. Developing high-sensitivity UV sensors based on $\mathrm{ZnO}$ nanorods grown on $\mathrm{TiO}_{2}$ seed layer films using solution immersion method. Sens. Actuators A Phys. 2020, 302, 111827. [CrossRef]

31. Zhang, X.; Ren, S.; He, X.; Dong, L.; Bai, W.; Lei, T.; Chen, H. Preparation and characterization of cellulose nanofiber/zinc oxide composite Films. J. Biobased Mater. Bioenergy 2020, 14, 203-208. [CrossRef]

32. Fan, B.; Yao, Q.; Wang, C.; Xiong, Y.; Sun, Q.; Jin, C. Spawns structure of rod-like ZnO wrapped in cellulose nanofibers for electromagnetic wave absorption. J. Nanomater. 2017, 2017, 6329072. [CrossRef]

33. Manekkathodi, A.; Lu, M.-Y.; Wang, C.W.; Chen, L.-J. Direct growth of aligned zinc oxide nanorods on paper substrates for low-cost flexible electronics. Adv. Mater. 2010, 22, 4059-4063. [CrossRef] [PubMed]

34. Gullapalli, H.; Vemuru, V.S.M.; Kumar, A.; Botello-Mendez, A.; Vajtai, R.; Terrones, M.; Nagarajaiah, S.; Ajayan, P.M. Flexible piezoelectric ZnO-paper nanocomposite strain sensor. Small 2010, 6, 1641-1646. [CrossRef] [PubMed]

35. Mun, S.; Kim, H.C.; Ko, H.-U.; Zhai, L.; Kim, J.W.; Kim, J. Flexible cellulose and ZnO hybrid nanocomposite and its UV sensing characteristics. Sci. Technol. Adv. Mater. 2017, 18, 437-446. [CrossRef] [PubMed]

36. Ko, H.-U.; Mun, S.; Min, S.-K.; Kim, G.-W.; Kim, J. Fabrication of cellulose ZnO hybrid nanocomposite and its strain sensing behavior. Materials 2014, 7, 7000-7009. [CrossRef] [PubMed]

37. Mun, S.; Ko, H.-U.; Zhai, L.; Min, S.-K.; Kim, H.-C.; Kim, J. Enhanced electromechanical behavior of cellulose film by zinc oxide nanocoating and its vibration energy harvesting. Acta Mater. 2016, 114, 1-6. [CrossRef]

38. John, A.; Ko, H.-U.; Kim, D.-G.; Kim, J. Preparation of cellulose-ZnO hybrid films by a wet chemical method and their characterization. Cellulose 2011, 18, 675-680. [CrossRef]

39. Nayak, J.N.; Chen, Y.; Kim, J. Removal of impurities from cellulose films after their regeneration from cellulose dissolved in DMAc/LiCl solvent system. Ind. Eng. Chem. Res. 2008, 47, 1702-1706. [CrossRef]

40. Hai, L.V.; Zhai, L.; Kim, H.C.; Kim, J.W.; Choi, E.S.; Kim, J. Cellulose nanofibers isolated by TEMPO-oxidation and aqueous counter collision methods. Carbohydr. Polym. 2018, 191, 65-70. [CrossRef]

41. Yun, S.; Kim, J. Mechanical, electrical, piezoelectric and electro-active behavior of aligned multi-walled carbon nanotube/cellulose composites. Carbon 2011, 49, 518-527. [CrossRef]

42. Yang, C.; Kim, J.-H.; Kim, J.-H.; Kim, J.; Kim, H.S. Piezoelectricity of wet drawn cellulose electro-active paper. Sens. Actuator A Phys. 2009, 154, 117-122. [CrossRef] 
43. Yun, S.; Kim, J.H.; Li, Y.; Kim, J. Alignment of cellulose chains of regenerated cellulose by corona poling and its piezoelectricity. J. Appl. Phys. 2008, 103, 083301. [CrossRef]

44. Schlaf, R.; Murata, H.; Kafafi, Z.H. Work function measurements on indium tin oxide films. J. Electron. Spectros. Relat. Phenomena 2001, 120, 149-154. [CrossRef] 